\title{
SEMIÓTICA PLÁSTICA E LINGUAGEM PUBLICITÁRIA
}

Análise de um anúncio da campanha de lançamento do cigarro "News"

I - Nota introdutória

Foi a pedido de estudantes de publicidade que estudamos um dos anúncios da campanha de lançamento do cigarro "News"' (1). Isso quer dizer que não abordamos este estudo com a preocupação de reencontrar e, menos ainda, de justificar o problema que tentamos elaborar há vários anos, o da semiótica plástica. Entretanto, muito antes que passássemos a trabalhar como consultor de publicidade, pensávamos que a semiótica plástica estava nela bem presente, na medida em que as condições de enunciação e os universos semânticos explorados não são ai intuitivamente muito diferentes daqueles que se encontram estudando a pintura figurativa, a fotografia de moda ou de "flagrante delito"

Tivemos, e teremos ainda, ocasião de mostrar aos publicitários o interesse da análise semiótica, retomando esse exemplo do anúncio do "News" Aqui, porém, para os semioticistas, desejaríamos não somente mostrar como se isolou sua dimensão plástica, mas também mostrar como ela se articula, de um lado, com a dimensão figurativa e, de outro, com o enunciado lingüístico que o anúncio comporta.

\section{II - Estudo do Significante do Anúncio}

A superfície total do anúncio (figura 1, p. 45)। divide-se em três faixas horizontais:

(1) Agência Intermarco-Conseil, 1980, campanha pela imprensa voltada para o grande público; responsáveis: Daniel Pascal e Jean-Louis Gruibout. 
1 a do alto compõe-se de linhas, traços e colunas tipográficas em paralelismo horizontal;

2 a do meio apresenta-se como um puzzle: todos os limites dos polígonos são oblíquos;

3 a de baixo constitui-se, como a do alto, de um paralelismo horizontal: o do conjunto da coluna tipográfica e de sua disposição em relação ao limite inferior do puzzle.

Se se considera apenas a faixa do meio, pode-se nela distinguir duas áreas:

2.1. uma área de polígonos cinza que cerca...

2.2. uma área retangular colorida (ver figura 2, pg.46).

Ora, esta impressiona pela semelhança com a superfície total do anúncio. Mesmo se ela não é senão uma parte da grande faixa do meio por seus limites oblíquos que se integram à rede geral, ela reproduz a mesma organização plástica: três faixas (relativamente) horizontais intercaladas:

2.2.1. uma faixa alta constituída de um paralelismo de elementos horizontais;

2.2.2. uma faixa intermediária que apresenta um entrelaçamento de linhas com dominância vertical;

2.2.3. uma faixa baixa composta, como a faixa alta. de um paralelismo de elementos horizontais.

O dispositivo geral do anúncio pode ser assim representado:

superfície total

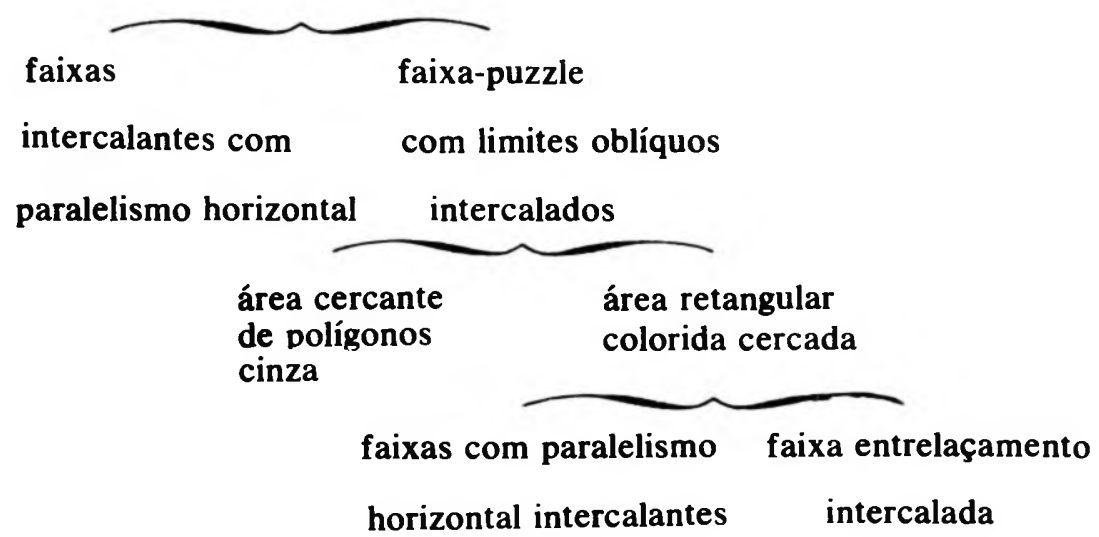


Esse dispositivo repousa sobre dois tipos de inclusōes:

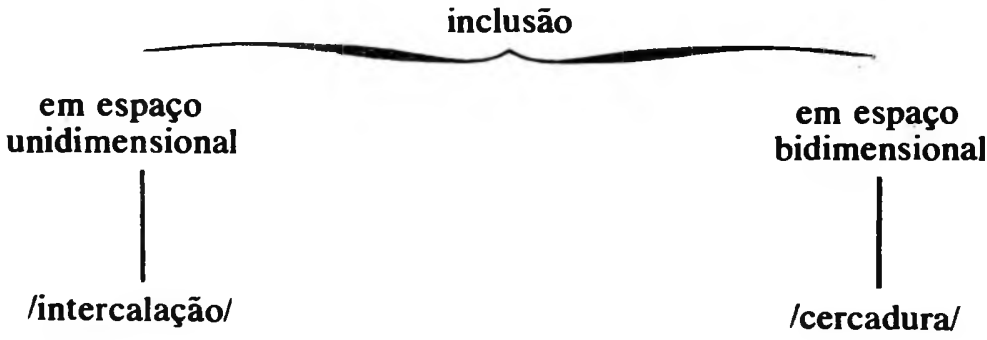

O fato de que é a parte inclusa que duas vezes se divide,determina um certo tipo de processo topológico que se poderia denominar "colocação em abismo"

Estudar-se-ão agora as diferentes qualidades de composição cromática e gráfica que se investem em cada uma das partes que se acabou de isolar.

O reconhecimento das categorias visuais exploradas nesse anúncio e a análise das relações entre seus termos realizados permitem mostrar que as partes inclusivas e inclusas da superfície total da faixapuzzle e da área retangular são, respectivamente, postas em contraste (toma-se aqui o termo no sentido preciso que lhe deu a semiótica visual): quer dizer que os termos opostos de uma mesma categoria são, cada um, realizados por uma das duas partes em relação de inclusão nesse anúncio.

a) organização da superfície total:

- composição gráfica:

paralelismo de horizontais $v s$ rede de oblíquas tangentes

- composição cromática:

jogo de cores puras vs jogo de valores

- disposição: intercalante vs intercalado

b) organização da faixa-puzzle:

- composição gráfica: emaranhamento (tangências não ortogonais) vs trama (tangências ortogonais)

- composição cromática: monocromatismo (gama de cinza)

vs policromatismo

- disposição: cercante vs cercado

c) organização da área retangular:

- composição gráfica:

paralelismo de horizontais $v s$ rede de linhas tangentes 
- composição cromática:

relações vivas $v s$ relações matizadas

- disposição:

intercalante $v s$ intercalado

Serão feitas duas observações a respeito dessas colocações em contraste.

1. A "semelhança" intuitivamente constatada mais acima entre a superfície total e a área retangular revelou-se fundada: ambas são organizadas a partir de uma intercalação em que áreas intercalantes e áreas intercaladas se opõem pelas mesmas relações de composição gráfica e cromática. $\mathrm{O}$ anúncio repousa assim sobre a homologação dessas duas unidades: tratar-se-á, então, de descobrir que papel exerce essa homologação na produção do sentido desse anúncio.

Três tipos de grafismo e três tipos de cromatismo servem para realizar os contrastes:

- graficamente:

a) paralelismos opõem-se a entrelaçamentos;

b) entrelaçamentos ortogonais a entrelaçamentos não ortogonais;

c) simetrias a assimetrias:

- cromaticamente:

a) cores puras opõem-se a um jogo de valores:

b) um policromatismo (vermelho, branco, marrom matizados) a um monocromatismo (cinza);

c) cores puras a cores misturadas.

2. Percebe-se, então, que a oposição fundamental no que tange ao grafismo é aqui /composição regular /vs/ composição irregular/ e que a oposição fundamental no que se refere ao cromatismo pode assim se denominar: / composição por saltos/ vs/ composição por graus/.

Ora, a regularidade oposta à irregularidade, assim como o salto oposto ao grau representam, sobre as duas dimensões respectivas do grafismo e do cromatismo, a mesma categoria última da descontinuidade oposta à continuidade. Era aliás previsível que o estudo das áreas e das superfícies do anúncio levasse a aí reconhecer a exploração de uma das grandes categorias que ordenam as projeções do espaço, quer essas projeções se façam por cores ou por entrelaçamentos de linhas.

Assim, o puzzle sem princípio de organização identificável, não oferece, ao contrário das faixas que apresentam um paralelismo, 
elementos geométricos isoláveis e concorre para produzir um efeito de continuidade de superfície. A mesma coisa se dá no caso da assimetria e da ausência de entrelaçamento ortogonal: o valor, a gama monocromática e o matiz exercem o mesmo papel na dimensão do cromatismo.

A geração dos diversos elementos reconhecidos nas unidades que compõem o anúncio pode ser representado do seguinte modo:

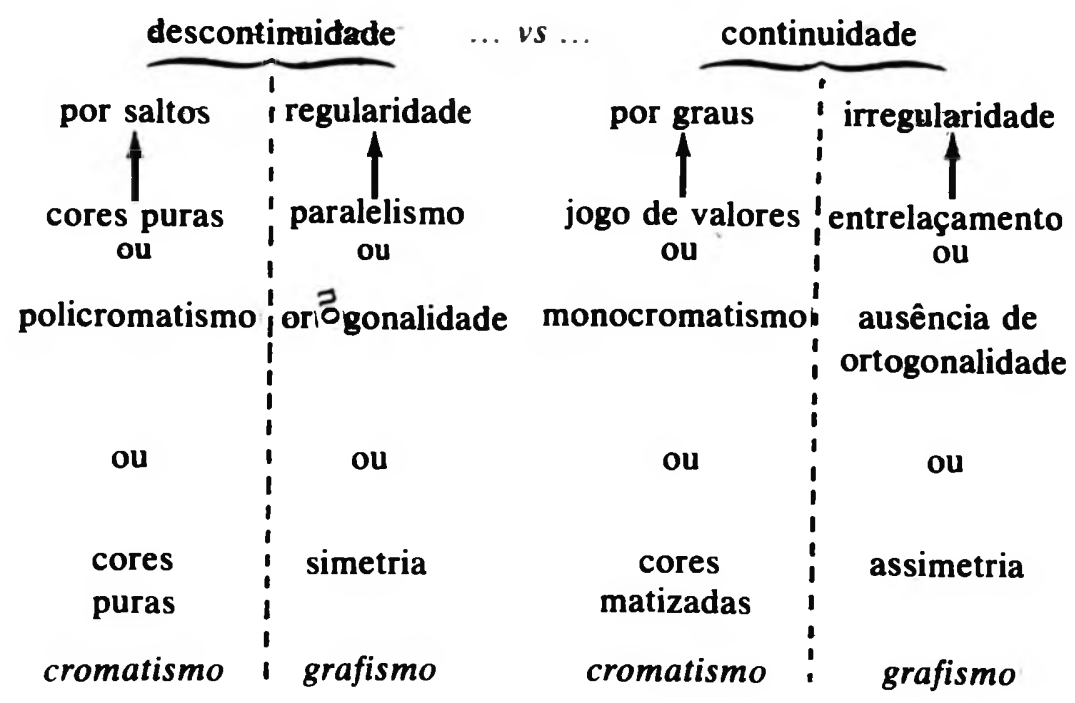

Para estudar a expressāo visual deste anúncio, dividiu-se primeiro a sua superfície para determinar o dispositivo de suas unidades, a fim de não isolar arbitrariamente esta ou aquela parte; em seguida, analisaram-se as qualidades de cor e de grafismo que as definem. Esse estudo chegou a dois resultados:

1. Sem ter, até este momento, recorrido à divisão pela identificação de objetos ou seres do mundo "re-produzido" identificaram-se três unidades em abismo: a superfície total, a faixa-puzzle e a área retangular. Observou-se que todas as três manifestam uma copresença de qualidades contrárias, de cor como de grafismo; e que duas dentre elas (a superfície total e a área retangular) eram homologáveis.

2. Por decomposições e aproximações sucessivas, extraiu-se o sistema que serve de base a essa expressão visual e descobriu-se que esse sistema tem de notável o fato de que, sob todos os pontos de vista, ele repousa sobre a exploração de uma mesma categoria última: 
descontinuidade vs continuidade e de que, ao mesmo tempo, cada uma das três unidades em abismo a realiza numa mesma relação topológica para as duas homologáveis e numa relação inversa para a faixa-puzzle.

A partir de agora, é preciso atacar a análise do conteúdo do anúncio para justificar o estudo das qualidades visuais como qualidades de expressão, isto é, como qualidades que têm algum papel na produção do sentido: não há expressão senão em relação a um conteúdo, não há significante senão em relação a um significado. Apenas as qualidades visuais que exercem um papel na produção do sentido são pertinentes para o estudo da significação. Essa preocupação com a pertinência é essencial e particularmente rentável em publicidade, porque ela permitirá controlar quais são as variações, as transformações de cor, de disposição na página ou de desenho que provocam uma mudança de sentido ou, ao contrário, quais são aquelas que não a provocam.

\section{III. - Estudo do Significado do Anúncio}

Para estudar o significado do anúncio, partir-se-á dos diferentes signos, palavras ou imagens, cujo encadeamento constitui a manifestação. $O$ anúncio, tomado em sua totalidade, representa a primeira página de um jornal: as palavras e os enunciados da parte superior são dispostos como o seriam o título e a divisa de um jornal. $\mathrm{O}$ aspecto jornalístico desses signos é reforçado pela utilização do "Times" * como caráter tipográfico. O próprio corpo da página constitui-se de grafemas e de imagens cuja disposição é a dos diferentes títulos, textos e fotografias da primeira página.

Pode-se, desde então, interrogar-se sobre o que recobre, como conteúdo de sentido, a noção de primeira página de um jornal. Ela é. evidentemente, se se considera a totalidade de páginas de um jornal, a primeira: aquela em que se dão as notícias que foram consideradas mais importantes, mais ricas de ensinamentos ou de emoções para os leitores; mas é também a página onde, cada dia, figura o título. Qualquer que seja o ordenamento das notícias, qualquer que seja o tamanho dos títulos em função da importância concedida aos acontecimentos, título e divisa constituem o lugar onde se manifesta a permanência do jornal. A primeira é, então, a página em que se manifesta uma das características fundamentais do discurso jornalístico: o de ser uma criação própria (no caso presente, coletiva) a partir destes “discursos dos outros" que são os acontecimentos do mundo.

* "Times" significa uma das famílias de caracteres empregados em tipografia (NT) 
Tomemos agora a imagem do anúncio. Que representa ela? Um maço de cigarros entreaberto colocado sobre fotografias dispersas. Elas são provas de ampliações, tal como saem do laboratório: é o jogo de clichês de que dispõe uma redação ou um diagramador que interrompeu, por um momento, o seu trabalho: selecionar, associar... A primeira página era o jornal pronto. Trabalho redacional ou diagramação, pouco importa, é agora o jornal no processo de se fazer. Resta, e é o essencial, que se trata aqui de dois percursos possíveis da performance jornalística: criar, dar uma significação nova e particular, explorando o que outros produziram e que tinha já sentido, valor.

Esses clichês esparsos sobre os quais se colocou o maço de cigarros não representam cenas quaisquer: são tomadas de tomadas. Uma fila de fotógrafos "metralhando" um "cameraman" que filma de um helicóptero: duas cenas de reportagem em pleno andamento; as roupas de um repórter sobre o capô de um Land-Rover, uma braçadeira da imprensa e material colocados diretamente no piso de um carro: duas cenas de reportagem por um momento interrompida. Os quatro clichês representam, em momentos e situações diversos, o trabalho do repórter fotográfico, primeiro anel da cadeia do discurso jornalístico: também ele, pelo enquadramento. a velocidade ou a profundidade do campo, realiza uma obra pessoal a partir dos gestos, das atitudes e das situaçōes significantes de outrem.

Tendo-se estudado a dimensão figurativa do anúncio, descobrese uma nova "colocação em abismo" situada desta vez no plano do conteúdo e que representa a performance deste sujeito coletivo sintagmático que é um "jornal" A personalidade do jornal (aqui "News") funda-se sobre a permanência de seu nome e de sua concepção de jornalismo, que vai mesmo além do corpo da primeira página, cada vez diferente. Essas primeiras páginas representam o trabalho regular e pessoal da redação e dos diagramadores a partir daquilo que thes fornecem os repórteres. Estes, enfim, criam seu próprio discurso (lingüístico ou fotográfico) a partir daquilo que lhes parece significativo nos propósitos e nas ações dos homens.

Tinha-se extraído, no plano da expressão, uma colocação em abismo entre três unidades: a superfície total, a faixa-puzzle e a área retangular. Ora, é forçoso constatar que as duas colocações em abismo não são homologáveis: se, por exemplo, a faixa-puzzle corresponde a esta unidade narrativa, que é a atividade dos redatores e dos diagramadores, não é a área retangular que representa a do trabalho dos repórteres. Dessa forma, deve-se propor agora a questão do papel da 
colocação em abismo das três unidades da expressão. Se elas não servem para a expressão desta narrativa que é a produção jornalística. elas, ao menos, colocam em relação este objeto jornalístico, que é a primeira página de um jornal, e este objeto aparentemente tirado de um universo totalmente outro: um maço de cigarros; e isso pelo tratamento das qualidades visuais das superfícies e áreas do conjunto do anúncio.

A homologação entre a superfície total do anúncio e a área retangular constitui a expressão de uma colocação em correspondência das significações de uma primeira página de um jornal e de um maço de cigarros. Que é esse maço de cigarros? Uma embalagem e um conjunto de cigarros dos quais somente, ou quase, os filtros são visíveis. Sobre a embalagem estão inscritas a marca e a divisa (as mesmas do jornal): "International News" "Take A Break In The Rush" assim como a qualidade particular do cigarro ("full flavor" "special blend") e a quantidade constante contida no maço (' 20 filter cigarettes'). Tantas são as manifestações de identidade do produto que essa identidade é concebida como permanência ou unicidade. Os cigarros of erecem esses tabacos selecionados cuja mistura especial é a criação própria do "News" Não é sem motivo que a imagem explora essencialmente a cor e a textura do papel que cerca os filtros, que lembram a mistura dos diferentes tabacos.

Pode-se, a partir de então, compreender o papel da homologação entre as qualidades de expressão da superfície total do anúncio e a área retangular que são os significantes respectivos da primeira página e do maço de cigarros: da mesma forma que o jornal é uma criação pessoal a partir de notícias selecionadas e compostas, o cigarro "News" é a criação de um penetrante aroma particular, graças a uma mistura especial de tabacos. O jornal e o cigarro "News" reúnem ambos identidade e alteridade: seu caráter próprio e permanente foi concebido a partir das qualidades de "matérias-primas" elaboradas por outras pessoas.

\section{IV. - Dimensão Plástica e Sistema Semi-Simbólico}

Deve-se lembrar que a superfície total do anúncio (o significante da primeira página) e a área retangular (o significante do maço de cigarros) são formadas de três faixas que estão na mesma relação topológica: duas faixas intercalantes construídas em descontinuidade e uma faixa intercalada construída em continuidade. Um mesmo contraste é assim realizado em cada um dos significantes e uma mesma oposição semântica organiza cada um dos significados. Ora, se se 
examina agora a que tipo de faixas é ligado cada termo da oposição semântica, constata-se que é a mesma reunião da oposição e do contraste que é colocada em jogo:

expressão: descontinuidade $v s$ continuidade conteúdo: /identidade/ vs /alteridade/

Essa junção, que é, repito, resultante da organização plástica da imagem (e que não existiria mais se essa organização fosse destruída), pode ser considerada como uma organização "profunda" no sentido que as duas relações agrupadas (descontinuidade vs continuidade e /identidade/ vs /alteridade/) são ambas situadas no nível profundo uma no do plano da expressão e outra no do conteúdo.

Deve-se propor uma última questão. Essa reunião explica também a terceira unidade de expressão: a faixa-puzzle? A junção estaria, então, no âmago da totalidade da significação manifestada neste anúncio.

Na faixa-puzzle, é a área englobante que é tratada como continuidade por uma composição em emaranhamento (não ortogonalidade das tangências) e por um monocromatismo cinza; e é a área retangular englobada que é tratada - em sua totalidade e em relação à área precedente - como descontinuidade por um paralelismo de horizontais e um policromatismo. Que representa a área englobante cinza? Os clichês dispersos dos repórteres. A área retangular é o significante do maço de cigarros, colocado sobre os clichês. Ele representa, metonimicamente, a atividade do redator ou do diagramador, mesmo que aqui ela esteja suspensa. Ver-se-á mais adiante a significação dessa pausa.

A faixa-puzzle, como já se viu, serve para a expressão da atividade de produção do jornal: os clichês constituem o discurso fornecido por outras pessoas que está sendo selecionado, reunido para compor finalmente o discurso do jornal. Em consequiência, reencontra-se de fato o mesmo agrupamento que estava em jogo na superfície total (a primeira página de um jornal) e na área retangular (o maço de cigarros): 


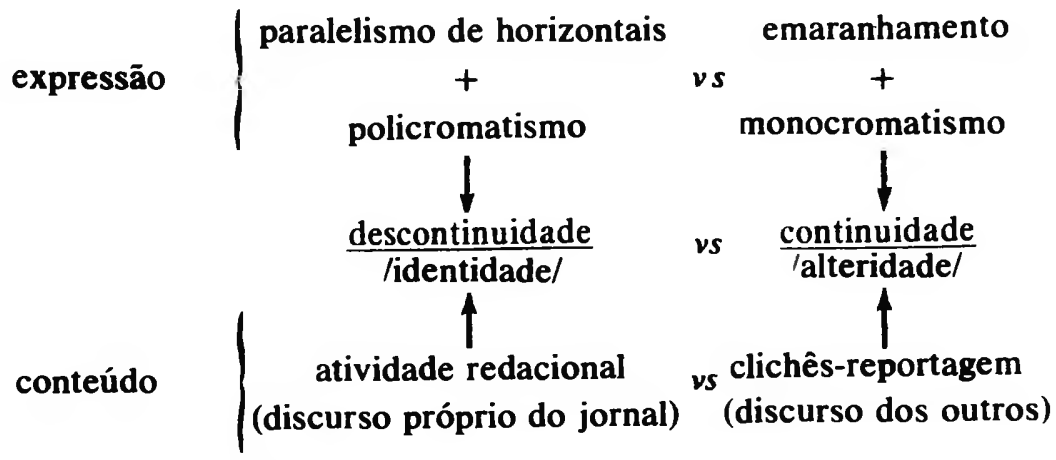

Foi estudando o papel da homologação da superfície total do anúncio e da área retangular que se colocou em evidência essa reunião da oposição (da expressão) descontinuidade vs continuidade e da oposição (do conteúdo) /identidade/ vs /alteridade/. Acaba-se de reencontrar essa mesma junção em jogo na organização da faixa-puzzle. isto é, na imagem do anúncio. Em conseqüência, ela está bem no âmago da significação do anúncio manifestado visualmente.

Mas que acontece com os enunciados lingüísticos?

Pode-se considerar que há de fato dois enunciados lingüísticos. Um é formado de palavras ou grupo de palavras em caracteres "Times" redondos, que manifestam a identidade e as qualidades do objeto: international News full flavor special blend 20 filter cigarettes;

o outro é constituído pela frase tomada como divisa e inscrita na faixa vermelha em "Times" itálicos. Este enunciado dá, de alguma maneira, a identidade abstrata, ideológica, do objeto, enquanto aquele manifesta a sua identidade figurativa. $O$ enunciado-divisa é assim para o enunciado das qualidades figurativas o que era a dimensão abstrata e ideológica da homologação plástica em relação à dimensão figurativa da primeira página e do maço de cigarros. Estudar-se-á, pois, esse enunciado-divisa como o lugar da manifestação lingüística de um conteúdo comparável àquele da dimensão plástica do anúncio.

Até o momento, esse enunciado não foi considerado senão na sua manifestação visual; interessou-se pela sua disposição paralela em relação às outras linhas horizontais, pela sua cor (em contraste com o fundo vermelho) ou ainda pela sua composição tipográfica (em "Times"'). É preciso agora estudar a expressão lingüística, mais precisamente oral, a que remete a manifestação visual, grafemática. Qual é o 
sentido da divisa? O leitor é convidado a quebrar o ritmo precipitado da vida social, a fazer uma pequena pausa em que será suspensa o que se chamava outrora a "presse"” Não se trata de aproveitar de um descanso concedido após o momento de agitação em que se deve desenvolver uma grande atividade, fumar um "News" é tomar a iniciativa de interromper momentaneamente o próprio fluxo da vida profissional... essa vida que alienaria se dela não se retomasse o controle, precisamente parando-a em intervalos mais ou menos regulares.

Ter-se-á compreendido que a significação do enunciado lingüístico repousa também sobre a oposição semântica/identidade/ vs/ alteridade/. O que o anúncio "News" propõe ao leitor é um estilo de vida que se pode qualificar de complexo no sentido de que ele reúne dois estados contrários: a participação na vida trepidante da sociedade (está-se em pleno movimento apressado da multidão) mas também a conquista de um estilo pessoal a ela impresso. Objeto de valor mítico, esse estilo de vida faz que se escape assim, ao mesmo tempo, ao isolamento e à alienação ou à privação do eu.

Interessamo-nos aqui pela significação relativamente abstrata da divisa, mas é possível identificar igualmente, num nível mais figurativo - o da narratividade de superfície - um jogo entre a forma verbal de "Take" e a apresentação do maço de cigarros entreaberto, como nos sugeriu Paolo Fabbri quando da apresentação desta análise na Escola de Altos Estudos.

Se se admite assim que o enunciado propōe como objeto-valor a adquirir pelo leitor um programa relativamente abstrato, compreenderse-á que esse estilo de vida (que é o do jornalismo: um jornal "fecha"; uma redação seleciona e corta; um diagramador reenquadra e um fotógrafo fixa o movimento) pode ser também o de toda situação em que se tem a possibilidade de organizar o próprio tempo de trabalho. Não é, no universo, sócio-profissional atual, a própria situação do executivo (após ter sido outrora a do artesão)? Observa-se que o estudo do anúncio chega aqui a dar o perfil do destinatário da campanha "News" antes mesmo que ele seja reconhecível neste ou naquele retrato profissional.

A profissão de repórter serve para uma comunicação particularmente eficaz deste privilégio que representa o estilo de vida "News", porque ela oferece uma figuratividade, um banco de imagens, de situações e de ações socialmente consideradas hoje como excepcio-

"Há aqui um jogo de sentido, pois "presse" significa pressa e imprensa. 
nais: observação direta do que se passa no mundo, criação intelectual ou estética, viagens (nas imagens suficientemente contrastadas na impressão, pode-se ler sobre um dos clichês, no alto do cartão postal colocado diretamente sobre o capô do Land-Rover, "Mongólia" e "Coréia"), meios sofisticados (helicóptero, Land-Rover, câmaras reflex), privilégios (braçadeira "Imprensa"), roupas descontraídas (impermeável com cinto, blusão)... O propósito do estudo é isolar o tipo de relação entre expressão e conteúdo colocado em jogo na produção do sentido do anúncio, o que implica abordagem metodologicamente bem distinta daquela praticada principalmente por $\mathbf{R}$. Barthes em seu artigo de 1964, "Retórica da imagem" (a respeito das “Massas Panzani” em Communications, $\left.\mathrm{n}^{\circ} 4\right)$. Aliás, já se terá notado que uma dimensão "retórica" tem certamente sua pertinência e sua importância - ela assegura a eficácia da comunicação do conceito (em publicidade, designar-se-ia assim, o estilo de vida /identidade/ + /alteridade/ associado ao cigarro a ser lançado) - mas que ela aí mostra seus limites: não é ela que está na origem do sentido ou, se se quer, que construiu o conceito. A retórica da imagem não intervém senão no momento em que o "conceito" se torna figurativo.

Voltemos à definição mais "abstrata" do estilo de vida que o enunciado lingüístico manifesta. Trata-se, com efeito, de perceber que esse enunciado reúne já, em seu contéudo, a /identidade/ à descontinuidade e a /alteridade/ à continuidade: a continuidade caracteriza o processo temporal que é o "rush"* (da vida social); assim como a descontinuidade distingue o dos "breaks"** que constituem o ritmo pessoal conquistado, ou a conquistar. Há aqui continuidade e descontinuidade no tempo (significado), enquanto o estudo da dimensão visual do anúncio tinha já isolado a descontinuidade e a continuidade no espaço (significante). Não obstante, por ter feito um rápido retorno à imagem a fim de mostrar sua retórica, tenha-se aí encontrado repórteres que enquadram e fixam uma redação que suspendeu por um momento sua seleção de clichês.

Assim, reencontra-se a oposição descontinuidade vs continuidade no plano do contéudo do enunciado lingüístico e ela aí articula os dois aspectos da temporalidade própria do estilo de vida associado ao cigarro "News" A oposição, com isso, "abandonou" o plano da expressão? Se sim, o agrupamento das duas oposiçōes seria, então, de natureza diferente no enunciado lingüístico.

* "Rush" significa pressa, precipitação, tropel, grande movimento, (NT)

** "Break" quer dizer interrupção, intervalo. (NT) 
De fato, o que há de notável nesse anúncio é que a oposição descontinuidade vs continuidade permanece, entretanto, uma oposição da expressão e que ela aí se junta, além disso, com a mesma oposição, semântica, ideológica: /identidade/vs/alteridade/.

Que ocorre, então, com a expressão sonora do enunciado lingüístico? Ela apresenta-se como uma organização binária: dois grupos de três silabas constituem "Take A Break In The Rush" Se se examina a natureza fonética de cada um dos dois grupos, percebe-se que o ritmo do primeiro repousa sobre consoantes oclusivas, isto é, consoantes cuja articulação comporta uma oclusão do canal oral seguida de uma abertura brusca:

Take A Break

e o que o ritmo do segundo grupo se assenta sobre constritivas, quer dizer, consoantes cuja articulação não comporta mais uma oclusão seguida de uma abertura, mas uma constrição:

In The Rush

Para ser preciso, o encadeamento de consoantes começa aqui por uma nasal (n), isto é, uma oclusiva, mas que pode ser "contida" (por sua posição final na sílaba): uma semi-oclusiva a segue (th), depois vêm uma constritiva vibrante (r) e uma constritiva fricativa (sh). Assim, essas diversas produções sonoras realizam, na primeira parte, um efeito de descontinuidade e, na segunda, um efeito de continuidade.

Se se consideram agora essas duas partes, essas duas unidades da cadeia da expressão sonora como os formantes (os significantes) das duas unidades semânticas, que são, de um lado, o convite a tomar a iniciativa de uma parada e, de outro, a micro-narrativa da vida social. reencontra-se a junção das duas oposições tal como ela tinha sido extraída no estudo da manifestação visual do anúncio:

expressão: descontinuidade $v s$ continuidade

conteúdo: /identidade/ vs /alteridade/

Depois de uma tal análise - e somente depois - percebe-se que o fato de haver um material sonoro e um material visual para a expressão do anúncio não implica que seja preciso considerá-lo como constituído de uma mensagem lingüística e de uma mensagem icônica. Nesse anúncio, material sonoro e material visual manifestam a mesma forma de expressão, a mesma estrutura de qualidades independentemente de suas manifestações.

Compreende-se melhor, de outro lado, como podem constituir-se as sinestesias, essas correspondências de sons, cores e perfumes. Elas não são de fato senão as manifestações em materiais sensoriais dife- 
rentes dos mesmos conjuntos de qualidades de expressão correlacionadas a este ou àquele conceito, quer essas correlações se façam por categorias (nos sistemas semi-simbólicos), quer unidade por unidade (nos sistemas simbólicos).

Pode-se representar, afinal, a relação entre a expressão e o conteúdo do anúncio da seguinte maneira:

Dimensāo visual

do anúncio
Dimensāo lingüística do anúncio

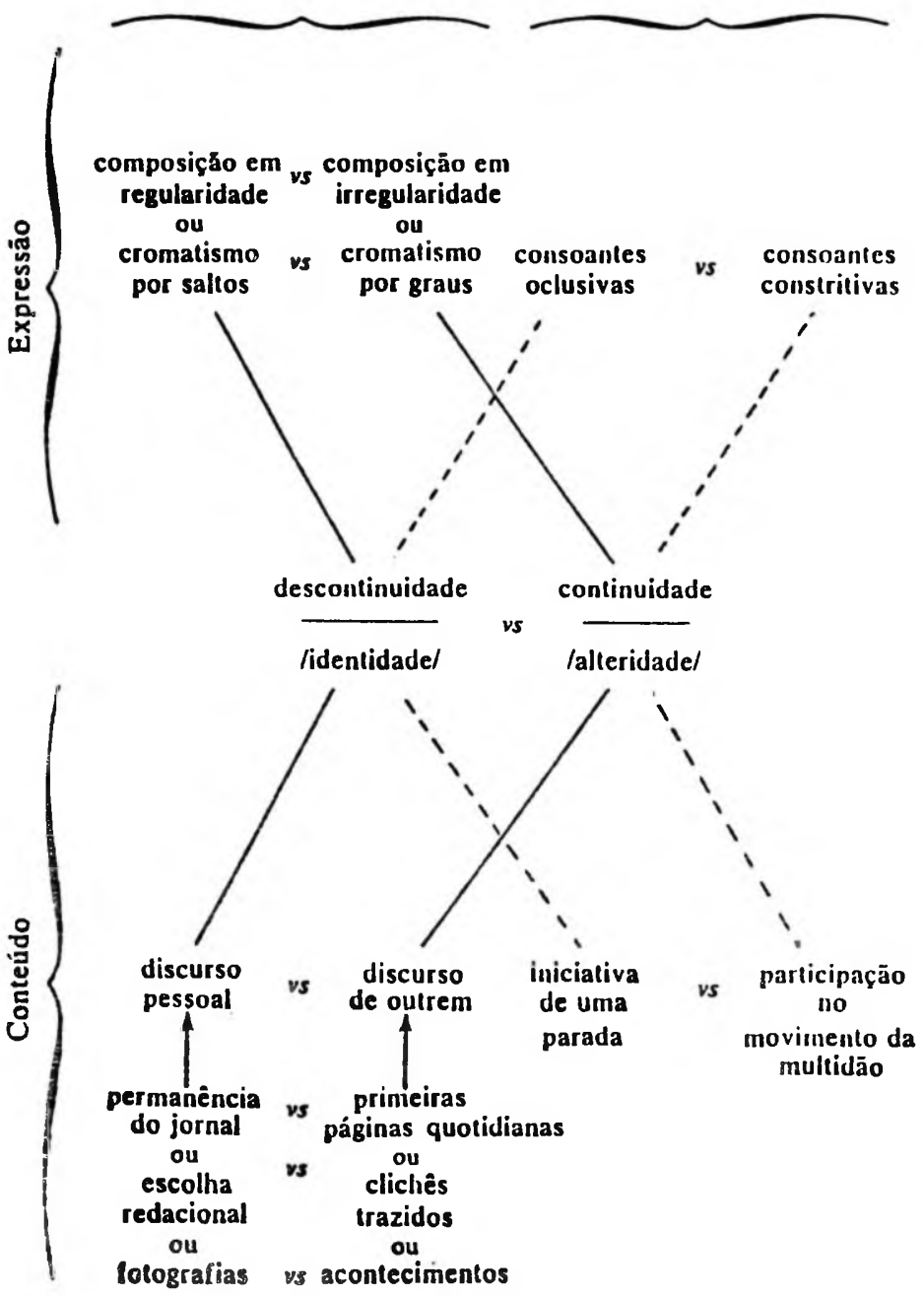


Serão feitas algumas observações sobre essa forma tão particular de relação entre plano de expressão e plano de conteúdo.

1. A significação desse anúncio repousa sobre um certo tipo de linguagem, chamada "semi-simbólica"; as linguagens semi-simbólicas caracterizam-se não pela conformidade de elementos da expressão e do conteúdo isolados, mas pela conformidade de certas categorias desses dois planos. Citam-se geralmente como formas semi-simbólicas singnificantes as formas prosódicas e certas formas de gestualidade. $O$ /sim/ e /não/ correspondem assim, em nosso universo cultural, à oposição dos movimentos da cabeça sobre os eixos verticalidade vs horizontalidade. A semiótica visual pôde mostrar a importância das organizações semi-simbólicas na pintura figurativa como na pintura abstrata e propôs chamar "linguagens plásticas" as linguagens visuais que manifestam uma semiótica semi-simbólica (1).

O que há de notável no anúncio aqui estudado é que o mesmo sistema semi-simbólico, a mesma junção de uma oposição de expressão e de uma oposição de conteúdo foi constituída a partir de duas linguagens de manifestação que não só diferem entre si pelos materiais em que se realizam, mas também se distinguem ambas do sistema semisimbólico, pois a imagem figurativa e o texto remetem. direta ou indiretamente, a estes dois sistemas simbólicos que são, respectivamente, o mundo natural e língua natural.

Pela reunião de uma oposição de expressão independente de todo material de manifestação e de uma oposição de conteúdo situada num nível abstrato, ideológico, o anúncio não só produz seu sentido, sua "mensagem" para além da distinção texto/imagem, mas também ele se dá a possibilidade de se realizar em múltiplos registros de expressão ou de conteúdo (temas ou universos figurativos) e produz enfim, se essa possibilidade é explorada, seu efeito de sentido de riqueza e de criatividade.

2. O esquema de representação da relação entre a expressão e o conteúdo do anúncio não explica um fenômeno observado quando do estudo do enunciado lingǘstico: a oposição descontinuidade vs continuidade, que se tinha isolado e situado sobre o plano da expressão para a dimensão visual do anúncio, articula também a temporalidade do estilo de vida valorizado na frase "Take A Break In The Rush" Dessa forma, poder-se-ia crer que a expressão visual e o conteúdo lingüístico devem ser homologados. De fato, após o estudo da expressão lingüísti-

(1) Uma coletânea de análises que ilustram a importância dessa problemática deve aparecer sob o título Introducién is linguagens visunis. Do abstrato a figurativo. 
ca sonora e uma rápida volta sobre as açōes representadas na imagem, notou-se que a oposição descontinuidade $v s$ continuidade, tanto para a frase como para a dimensão visual do anúncio, é utilizada não só como oposição de expressão, mas também como oposição do conteúdo (desta vez relativamente superficial). Repetimos, tal fenômeno não deve surpreender: uma linguagem é antes de tudo uma rede de relações, de oposições conceituais - de "categorias semânticas" na terminologia semiótica; elas podem, então, servir para constituir o plano da expressão ou o plano do conteúdo... ou ainda (como é o caso aqui) a expressão e o conteúdo, criando um efeito de motivação do signo, de permeabilidade dos dois planos da linguagem normalmente e teoricamente - unidos de maneira totalmente arbitrária.

3. A publicidade seria o refúgio da poesia? Para justificar a incongruência de tal questão, notar-se-á que o fato de a significação do anúncio repousa sobre a acoplagem de oposiçōes de expressão e de conteúdo pode ser considerado como característica da produção poética, no sentido que, como na poesia manifestada lingüisticamente, o anúncio joga (a) com a indentificação de articulaçōes paralelas e correlatas que envolvem os dois planos, expressão e conteúdo, (b) com a colocação do enunciado em sistema: Roman Jakobson diria com a "projeção do eixo paradigmático sobre o eixo sintagmático"

Ademais, poder-se-ia dizer que esse anúncio é "poético" pelo tipo de discurso que ele produz. Com efeito, a análise sintáxica narrativa que dele se pode fazer (a proposição de um estilo de vida complexo, isto é, ao mesmo tempo /identidade/ e /alteridade/ dá esse discurso como um discurso abstrato, enquanto, semanticamente, é um discurso figurativo, ao menos em sua dimensão mais explorada: a dimensão visual. Esse privilégio concedido à dimensão visual e à exploração de sua figuratividade para comunicar uma mensagem abstrata, ideológica, faz desse anúncio um enunciado muito próximo dos enunciados míticos ou sagrados que, usando do mesmo tipo de discurso, ao mesmo tempo, sintaxicamente abstrato e semanticamente figurativo, produzem um efeito de sentido de verdade.

\section{V - Os outros anúncios da campanha}

O anúncio que acaba de ser estudado não é a única manifestação da campanha de lançamento do cigarro "News" Entre a meia dúzia de outros, dois somente retomam o tema da reportagem. Um (figura 3) representa em uma mesma faixa-puzzle central um maço de cigarros 
deitado sobre clichês e também - o que é novo - sobre seus contatos*; um cigarro está tirado do maço e colocado ao longo do seu lado direito. $O$ outro anúncio (figura 4) representa o maço em pé. Seu perfil está inscrito em baixo do único clichê, o dos repórteres que "metralham" Nesse anúncio, menciona-se a indicação "20 filter cigarettes" em uma pequena faixa branca oblíqua a cavaleiro do clichê e da divisa. $O$ anúncio foi muitas vezes publicado na quarta página de capa de revista; ele é, então, circundado de uma cercadura vermelha. Os outros anúncios (figura 5) apresentam também o maço em pé, mas sobre uma espécie de mostrador abstrato cujo fundo vertical, para certas pessoas, constitui-se da faixa superior do anúncio estudado: o paralelismo horizontal do "título" e da "divisa"

A partir do estudo comparativo das diferentes dimensões visuais desses anúncios, pode-se notar que somente o anúncio que representa o maço deitado sobre clichês e contatos (fig. 3) reproduz o tratamento plástico do anúncio estudado (fig. 1). E cremos dever insistir nisso: o mesmo tratamento plástico é reproduzido, embora a parte inclusa na faixa-puzzle não seja só a área retangular do maço, mas as duas áreas disjuntas do maço e do cigarro. Em outras palavras, a mesma estrutura plástica, o mesmo jogo de contrastes gráficos e cromáticos e de suas disposições aí se reencontram, ao passo que os signos mudaram, que o plano da manifestação constitui-se, figurativamente, de uma outra cadeia de unidades significantes. Tal exemplo mostra a independência de fato - de direito, estava adquirida teoricamente por definiçāo — da forma plástica em relação à sua realização em signos. Se se considera, enfim, o mundo publicitário (e se se fala sua linguagem), vê-se o partido que, praticamente, dele pode tirar o "criativo" no que tange à "declinação" possível do anúncio estudado.

Interessemo-nos agora pelo anúncio que foi, muitas vezes, publicado na quarta página da capa (figura 4). Dois elementos aí se encontram, que subvertem a organização da dimensão visual em relação à do anúncio estudado:

a) a cercadura vermelha exclui toda possibilidade de homologação da superfície total do anúncio e da área do maço de cigarros. Ora, todos se lembram de que era essa homologação que fundava, segundo nossa posição, a significação profunda do primeiro anúncio e, ao mesmo tempo, o valor do maço de cigarros "News";

b) a pequena faixa branca oblíqua rompe o paralelismo da divisa e

- Contato significa conjunto de provas, fotográficas dispostas numa mesma prancha para que se selecionem as que se deseja. 
sobretudo a separação entre a faixa superior e faixa central; bem mais, essa faixa oblíqua se constitui como espaço incluso em relação ao conjunto de todo o anúncio - espaço inclusivo. A disposição geral da superfície total do primeiro anúncio é, então, inteiramente destruída.

Se se verifica que, em relação ao anúncio estudado, o maço de cigarros perde assim toda sua riqueza semântica, dois outros elementos, figurativos desta vez, dissociam-no da "narrativa" desenvolvida pelos dois anúncios (figuras 1 e 3) que representam vários clichês de reportagem:

a) a inscrição do perfil do maço de cigarros no único clichê que aparece, o dos repórteres "metralhando", não o apresenta mais como maço utilizado pelos jornalistas - enquanto, nos outros anúncios, ele estava colocado sobre o capô do Land-Rover ou, em todo caso, jogado por um redator ou um diagramador sobre um monte de clichês e/ou de contatos;

b) sua posição em pé, enfim, antes o apresenta, se se pode dizer, do que o deixa em condição de ser apanhado para tirar o cigarro que está ligeiramente de fora - e é, aliás, nessa posição em pé que o maço é colocado em um decor abstrato, se comparado com os outros anúncios (figura 5).

$\mathrm{O}$ que nos importava de fato neste (extremamente rápido) estudo comparativo era mostrar como a forma plástica, que determina a significação do anúncio estudado, podia ser reencontrada, apesar de certas transformações - no nível dos signos - e, outras vezes, perder-se desde que a organização cromática e gráfica fosse diferente.

\section{VI - Conclusão}

A semiótica plástica: uma reflexāo sobre a liberdade irreprimível dos "fabricantes de imagens".

Há alguns anos, tentamos definir a autonomia e a importância de uma "semiótica plástica" ao lado de uma semiótica figurativa. Por seus jogos de constrastes ou de ritmos, o tratamento gráfico e cromático de uma imagem opera, muitas vezes, uma supra-segmentação, que rearticula os signos figurativos, na maioria das vezes lexicalizáveis, e dota de formantes o discurso "profundo" do enunciado, discurso tímico, mas sobretudo axiológico. Essa pesquisa, começada pelo estudo do estatuto semiótico dos contrastes na fotografia de Edouard Boubat ( $\mid$ cf.i J.-M. Floch, "Sémiotique poétique et discours mythique 


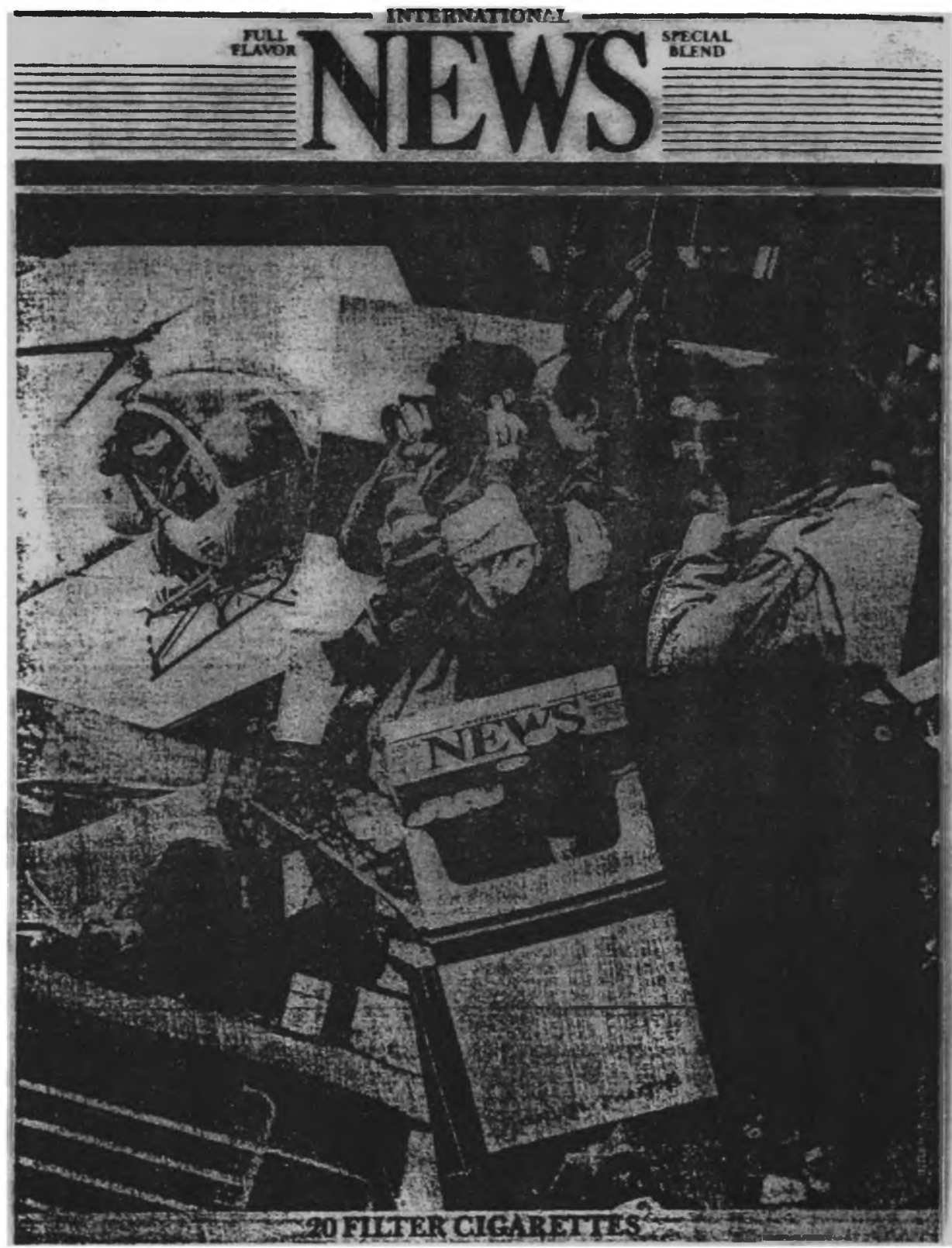

Figure 1 


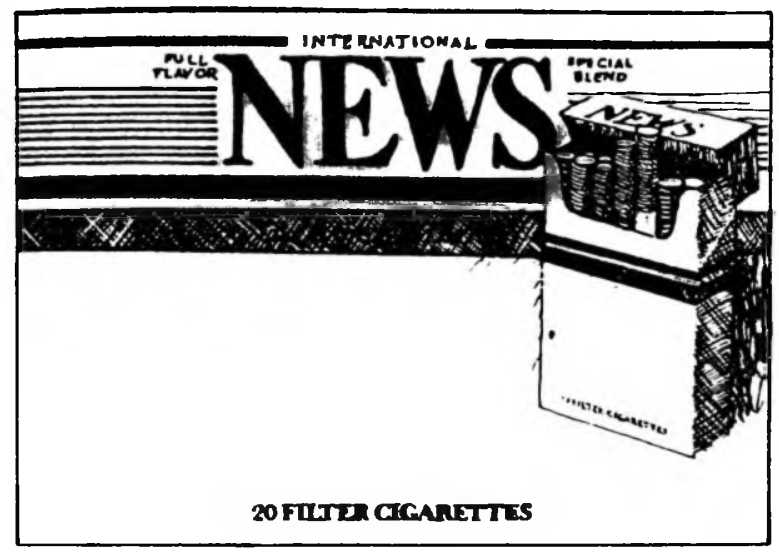

Figure $5 a$

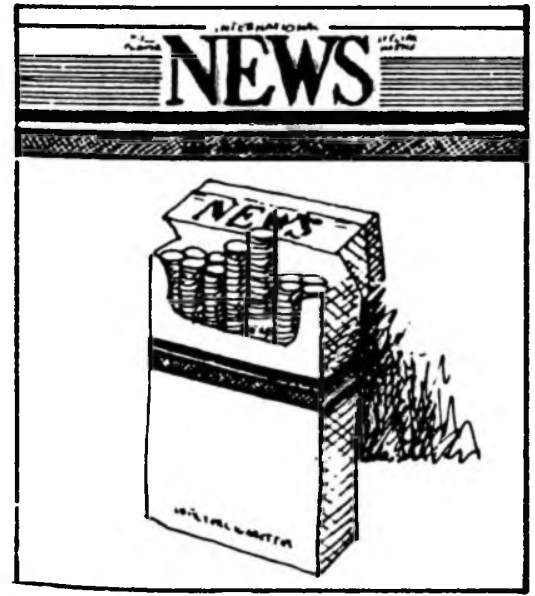

Figure $5 b$

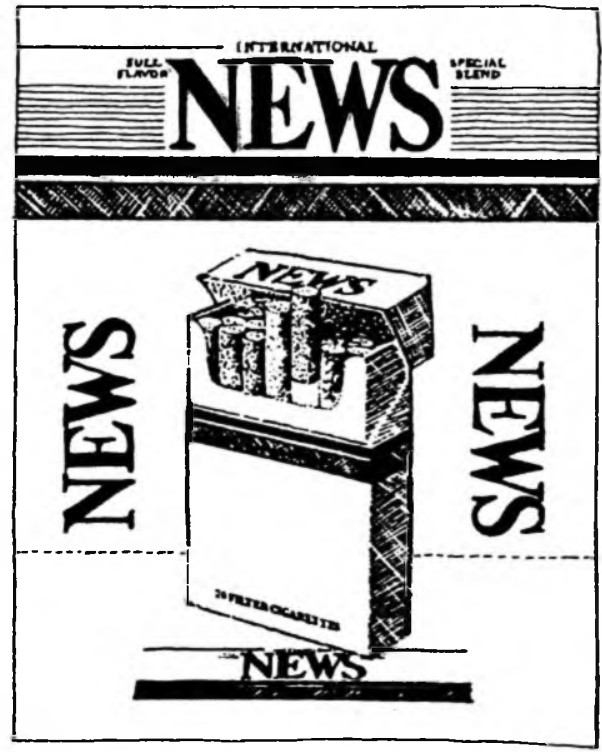

Figure $5 \mathrm{c}$ 


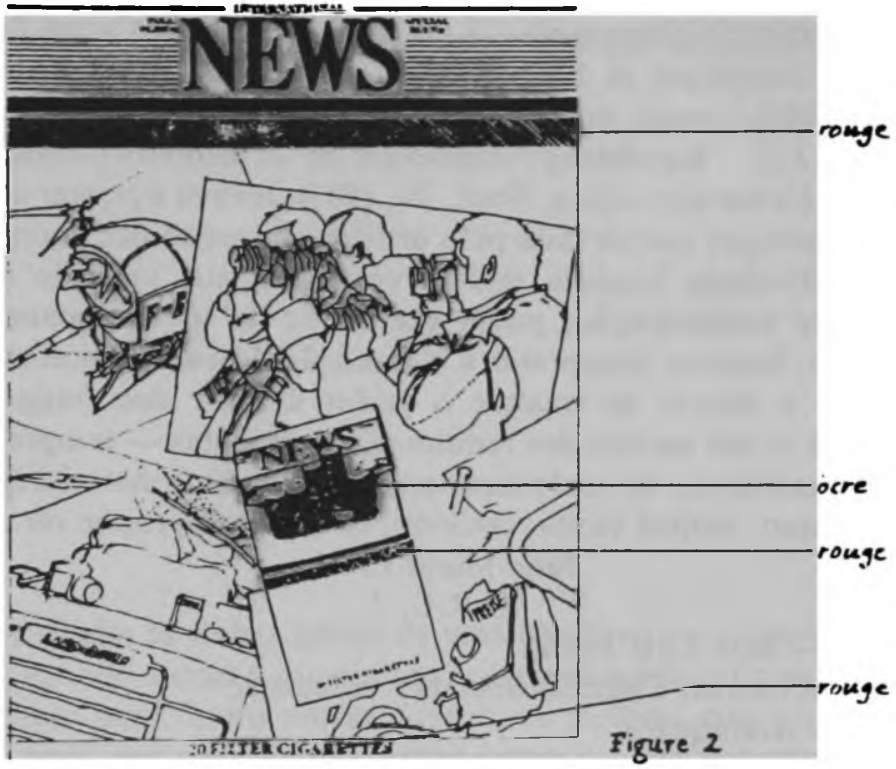

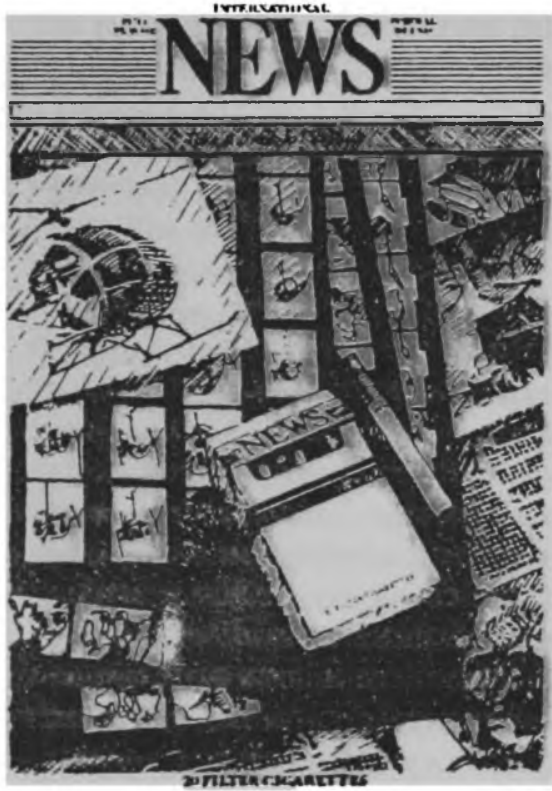

Figure 3

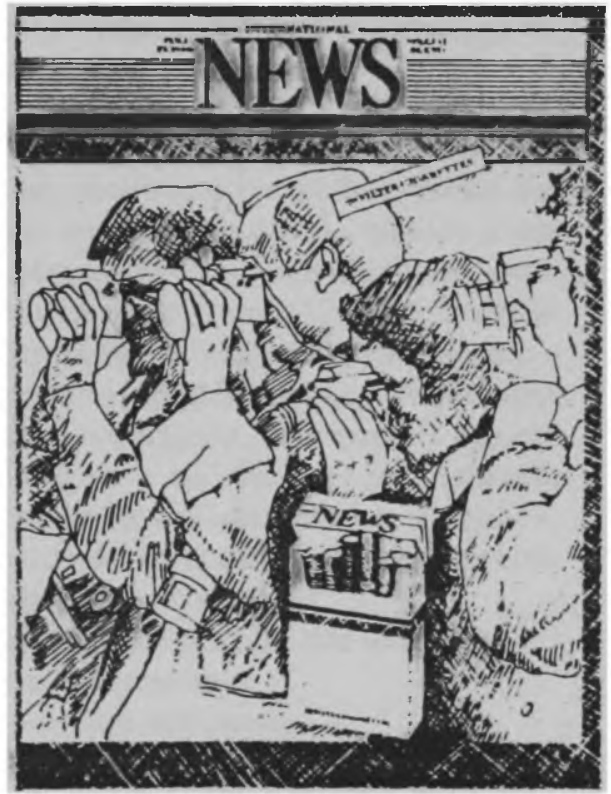

Firure 4 
en photographie" Documents et Pré-publications du Centre International de Sémiotique et Linguistique, Universidade de Urbino, 94, junho de 1980), depois desenvolvida pela análise de pinturas figurativas ou não ( cf. "Kandinsky: sémiotique de un discours plastique non figuratif" Communications, Seuil, 34, 1981), levava a pensar que essa liberdade, sempre conservada pelo artista a despeito das coerções de uma figuratividade imposta muitas vezes por sua inserção em um processo de comunicação, podia exercer-se da mesma maneira em publicidade. Pode-se interpretar a elaboração dessa "semiótica plástica" como o desejo de exaltar o poder criador dos fotógrafos e desenhistas - até mesmo dos redatores e dos poetas - sempre livres, em última instância, de enriquecer ou de subverter o material figurativo, ou mesmo, muitas vezes, retórico, que se lhes propõe ou impõe.

Jean-Marie Floch

U.R.L. 7

Tradução - José Luiz Fiorin

Instituto de Letras, Ciências Sociais e Educação

UNESP - Araraquara 